\title{
On Tree Detection, Counting \& Post- Harvest grading of fruits Based on Image Processing and Machine Learning Approach-A Review
}

\author{
Prabira Kumar Sethy ${ }^{\# 1}$, Shwetapadma Panda ${ }^{* 2}$, Santi Kumari Behera ${ }^{\# 3}$, Amiya Kumar Rath ${ }^{\# 4}$ \\ ${ }^{\#}$ Department of Electronics, , Sambalpur University and, Jyoti Vihar,Burla,Odisha \\ Veer Surendra sai University of Technology, Siddhi Vihar,Burla,Odisha \\ 1.prabirsethy.05@gmail.com \\ ${ }^{3}$ b.santibehera@gmail.com \\ 4amiyaamiya@rediffmail.com \\ ${ }^{2}$ shwetapadma.panda@suiit.ac.in
}

\begin{abstract}
This paper reports involvement of image processing and machine vision technique to detect and count of fruits on-tree, in field condition, have been reviewed. In addition, this paper also associated with the grading of fruits in post-harvesting. Different types of algorithms are available for counting and to extract the feature of fruit characters by capturing the on-tree fruit image by any conventional RGB camera. With the help of this counting algorithm and feature extraction technique, fruit is detected and counted. This work also surveys grading method applied to the post-harvest fruits. Grading method involves: identification of mature \& immature fruits, intact \& diseased fruits and also predict the weight of the fruit from its shape. The grading of fruit can be done by using different types of the classifier. The main features, drawback and future prospective of previous work in this area are summarized.
\end{abstract}

Keyword- On-tree detection \& counting of fruits, Post-harvest grading of fruits, K-Means clustering, Histogram method, HSI technique, color-mapping, RGB color space method, SVM, KNN, ANN, Fuzzy logic.

\section{INTRODUCTION}

Now a day's human life is very busy. Everyone wants to do their work within a very few time, accurately and in low cost. So this type of desire can only fulfill by the advance technology. So various research works have been doing by the various researcher to get an accurate result. Fruit counting is time taking and need large manpower with more cost. So to avoid these types of problem it is necessary to have automatic fruit detection and counting algorithm for better performance. Grading of fruits in the fresh form for quality is essential, as the people are quality conscious day by day. Grading of fruits after harvesting is an essential step in post-harvest management. Grading of fruits on basis of physical characteristics like weight, size, color, shape \& freedom from diseases depending upon agro climatic conditions. But for such grading large expertise man power is required. To overcome this it is necessary to have an automatic fruit grading system, to class different grade. It is indispensable to have non-destructive automatic quality detection technology in order to improve fruits quality detection, the system should have grading efficiency and reduce labor requirement. Fruit non-destructive detection is the process of detecting fruits by each side without damaging the fruit by using several detecting methods to do evaluation according to various standard rules. Today it is somewhat difficult to detect fruit shape, size, color because of a poor process, but it is now easy to detect correct fruit by using vision detecting method. For international market three general grads are considered as: Extra class, Class $1^{\text {st }}$, Class $2^{\text {nd }}$.

Advantages of Grading

- Losses the selling price due to presence of substandard products or specimen can be easily avoided.

- It increased marketing efficiency by facilitating buying and selling a produce without personal selection.

- Grading enhanced to set good price for graded products.

- Heavy marketing cost in packing and transportation can be avoided by grading.

- In grading diseased and defected specimen are not damaged due to contact of diseased specimens and thus gets high price in market.

- By grading there is fairness to both buyer and sellers.

- Properly graded vegetables and fruits are purchased by the consumer easily without inspection.

At present, several existing fruit quality detecting and grading technology have the demerit of low efficiency, low speed of grading, high cost and complexity. So it is necessary to develop faster speed and low-cost fruit size 
detecting and grading system. Here, the relationship between meta theory, methodology \& method was explored which are used for detecting, counting and grading of fruits, so as to retrieve the best suitable techniques for implementation which fulfills all the necessary requirements.

\section{RELATED WORK}

Machine vision and computer vision have been mainly used for the quality analysis and grading of fruits and vegetables. These have the capability to automate manual grading processes and minimize monotonous inspection tasks. Computer vision method is mainly used for defective part identification, classification and finding the ripeness of fruits based on their appearance. Randomized Hough transform is used for elliptical shape detection. Robotic harvesting and sensor technology are used for automation. This work summarize the review of the various work using different image processing and machine learning technique such as K-means clustering, fuzzy logic, artificial neural network (ANN), support vector machine (SVM), histogram technique, RGB color space technique, color mapping technique, pixel spectral process, approach of bag-of-words, wavelet transform, morphological operation and watershed transform.

\section{A. K-means Clustering}

$\mathrm{K}$-means clustering is a vector quantization method. It is very popular for cluster analysis. This method aims to partition $\mathrm{n}$ observations into $\mathrm{k}$ clusters in which each observation belongs to the cluster with the nearest mean, shown in Figure 1.
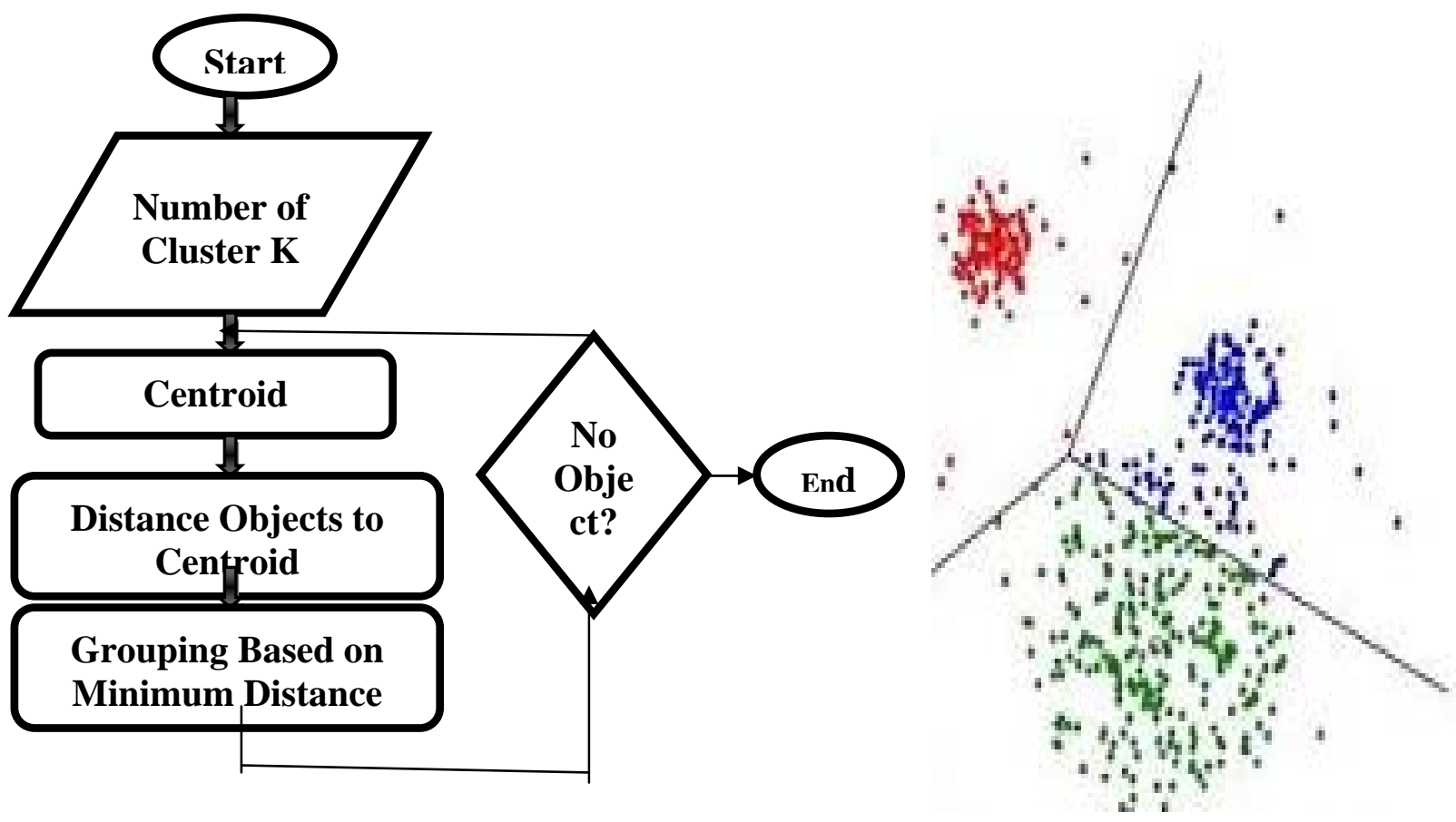

Figure 1. K-Means Clustering Method

Y. Song et al. ${ }^{[1]}$ have presented automatic fruit recognition and counting from multiple fruit images. In this case feature extraction using (MSCR, BOW model) in frequency domain and SVM classifier is the major image processing method. K-means clustering is used for segmentation of the image. In this case, it has achieved a correlation of $74.2 \%$ between automatic and manual counts of fruit. Zeeshan Malik et al. ${ }^{[2]}$ have described ontree citrus fruit detection and counting for yield estimation of crop. The database has been created for 83 tree image samples with 4001 citrus fruits from three different fields. K-means segmentation is used for recognition of fruits. The accuracy of the on-tree fruit detection was $91.3 \%$. The correlation between the manual and the automated count of fruits having coefficients of determination R2 up to 0.99 . Mohammad Bagher Lak et al ${ }^{[3]}$ have described machine vision technique, for identification of apple fruits at the first stage of robotic harvesting. Image processing algorithm, fruit detection, apple harvesting methods are used. In this paper, k-means clustering is used for unsupervised classification. This algorithm was finally assessed. This method has ability to identify apple fruits with $83.33 \%$ and detect its locations with a precision of $85.17 \%$. K. Parvati et al. ${ }^{[4]}$ have proposed image segmentation using gray-scale morphology and marker-controlled watershed transformation. For unsupervised classification k-means clustering was used. K-means is a learning algorithm, which separates the input data set into different clusters based on their inherent distance between each other. It minimizes the sum of the distance between the objects and respective cluster centres. It is an iterative process, which moves objects between the clusters until the sum is no longer minimized. Radnabazar Chinccullue et al. ${ }^{[5]}$ have 
described citrus yield mapping system by using machine vision technique. This paper presents machine vision technique with two charged coupled device, ultrasonic sensor and a differential global positioning system to estimate fruits. Amruta Pandit et al. ${ }^{[6]}$ described object counting using image processing techniques. In this case, k-means clustering was successfully segmented the image which was taken by a conventional camera (Table 1).

Table 1

\begin{tabular}{|c|c|c|}
\hline \multicolumn{3}{|c|}{ Analysis of Algorithm Related to K-MEANS Clustering } \\
\hline Authors \& Years & Goals & Future Prospective \\
\hline $\begin{array}{l}\text { Y. Song et al. have presented } \\
\text { automatic fruit recognition and } \\
\text { counting from multiple images. } \\
(2014)\end{array}$ & $\begin{array}{l}\text { K-means clustering is used for } \\
\text { segmentation of the image. }\end{array}$ & $\begin{array}{l}\text { By using the K-means } \\
\text { method, we can segment any } \\
\text { kind of fruits and vegetables. }\end{array}$ \\
\hline $\begin{array}{l}\text { Zeeshan Malik et al. have } \\
\text { described on-tree detection and } \\
\text { counting of citrus fruit for yield } \\
\text { estimation of crop.(2016) }\end{array}$ & $\begin{array}{l}\text { K-means segmentation is used for } \\
\text { recognition of fruits. They are able to } \\
\text { detect the on-tree fruits with an } \\
\text { accuracy of } 91.3 \% \text {. }\end{array}$ & $\begin{array}{l}\text { Since it gives the very } \\
\text { accurate result, we can use this } \\
\text { method in various cases. }\end{array}$ \\
\hline $\begin{array}{l}\text { Mohammad Bagher Lak et al. have } \\
\text { described Machine vision recognition } \\
\text { algorithm at the first stage of apple } \\
\text { robotic harvesting.(2006) }\end{array}$ & $\begin{array}{l}\text { In this paper, machine vision is } \\
\text { used for unsupervised classification. } \\
\text { This algorithm was finally assessed. }\end{array}$ & $\begin{array}{l}\text { Unsupervised classification } \\
\text { will also use in future } \\
\text { prospective. }\end{array}$ \\
\hline $\begin{array}{l}\text { K. Parvati et al. described image } \\
\text { segmentation using gray-scale } \\
\text { morphology and marker-controlled } \\
\text { watershed transformation.(2010) }\end{array}$ & $\begin{array}{l}\text { For unsupervised classification k- } \\
\text { means clustering was used. K-means } \\
\text { is a learning algorithm, which } \\
\text { separates the input data set into } \\
\text { different clusters based on their } \\
\text { inherent distance between each other. }\end{array}$ & $\begin{array}{l}\text { This method will also very } \\
\text { useful in classification. }\end{array}$ \\
\hline $\begin{array}{l}\text { Radnabazar Chinccullue et al. } \\
\text { described citrus yield mapping } \\
\text { system using machine vision } \\
\text { technique.(2006) }\end{array}$ & $\begin{array}{l}\text { K-means clustering was used to } \\
\text { classify the fruit samples. }\end{array}$ & $\begin{array}{l}\text { This method will also very } \\
\text { useful in classification and } \\
\text { segmentation. }\end{array}$ \\
\hline $\begin{array}{l}\text { Amruta Pandit et al. described } \\
\text { object counting using image } \\
\text { processing techniques.(2014) }\end{array}$ & $\begin{array}{l}\text { In this case, k-means clustering } \\
\text { was successfully segmented the } \\
\text { image which was taken by a } \\
\text { conventional camera. }\end{array}$ & $\begin{array}{l}\text { This method will very } \\
\text { helpful in any kind of } \\
\text { vegetable and } r \text { fruits } \\
\text { segmentation. }\end{array}$ \\
\hline
\end{tabular}

\section{B. Histogram Method}

Table 2

\begin{tabular}{|c|c|c|}
\hline \multicolumn{4}{|c|}{ Analysis of Algorithm Related to Histogram Method } \\
\hline \multicolumn{1}{|c|}{ Authors \& Years } & \multicolumn{1}{|c|}{ Goals } & Future Prospective \\
\hline $\begin{array}{l}\text { D. S. Jayas et al. have proposed } \\
\text { multi-layer neural networks for } \\
\text { image analysis of agricultural } \\
\text { products.(2008) }\end{array}$ & $\begin{array}{c}\text { In this case, the histogram of these } \\
\text { pixels shows the brightness distribution } \\
\text { found in the object. }\end{array}$ & $\begin{array}{c}\text { We will implement this } \\
\text { method in future also for } \\
\text { better performance. }\end{array}$ \\
\hline $\begin{array}{l}\text { Libin Zhang et al. have proposed } \\
\text { recognition of greenhouse cucumber } \\
\text { fruit using computer vision.(2010) }\end{array}$ & $\begin{array}{l}\text { In this case, some descriptors of } \\
\text { texture based on the intensity histogram } \\
\text { were obtained such as mean, standard } \\
\text { deviation, smoothness, third moment. }\end{array}$ & $\begin{array}{l}\text { In future also we can use } \\
\text { this method for calculation of } \\
\text { properties. }\end{array}$ \\
\hline $\begin{array}{l}\text { Zania S Pothen et al. have } \\
\text { proposed texture-based fruit } \\
\text { detection via images using the } \\
\text { smooth pattern recognition of the } \\
\text { fruit.(2007) }\end{array}$ & $\begin{array}{l}\text { Candidate fruit locations that pass the } \\
\text { initial filter are classified using } \\
\text { modified histogram of oriented } \\
\text { gradients combined with pairwise } \\
\text { intensity comparison texture descriptor } \\
\text { and random forest classifier. }\end{array}$ & $\begin{array}{l}\text { For comparison of various } \\
\text { methods, we will use the } \\
\text { histogram technique. }\end{array}$ \\
\hline
\end{tabular}




\begin{tabular}{|c|c|c|}
\hline $\begin{array}{c}\text { Palaniappan Annamalai et al. } \\
\text { have proposed citrus yield mapping } \\
\text { system using machine vision.(2003) }\end{array}$ & $\begin{array}{l}\text { In this paper images of the citrus } \\
\text { grovere analysed and histogram \& } \\
\text { pixel distribution of various classes } \\
\text { (citrus, leaf, and background) were } \\
\text { developed. }\end{array}$ & $\begin{array}{l}\text { Analysis of various } \\
\text { methods will possible in } \\
\text { future work. }\end{array}$ \\
\hline $\begin{array}{c}\text { Annamalai et al. have described } \\
\text { papaya size grading using central } \\
\text { profile analysis of digital } \\
\text { image.(2010) }\end{array}$ & $\begin{array}{l}\text { Otsu's method for automatic } \\
\text { threshold selection from a histogram of } \\
\text { the image was successfully applied to } \\
\text { various segmentation cases. }\end{array}$ & $\begin{array}{c}\text { Histogram method will } \\
\text { also use in segmentation } \\
\text { purpose. }\end{array}$ \\
\hline $\begin{array}{l}\text { Q. M. Jonathan Wu et al. have } \\
\text { proposed a fruit recognition method } \\
\text { for automatic harvesting.(2009) }\end{array}$ & $\begin{array}{l}\text { Here shape-based pattern recognition } \\
\text { is efficient and accurate by using depth } \\
\text { histogram representation. }\end{array}$ & $\begin{array}{c}\text { For any type of line, } \\
\text { circle, ellipse detection we } \\
\text { will use this method. }\end{array}$ \\
\hline $\begin{array}{l}\text { Sashi. D.Buluswar et al. have } \\
\text { proposed colour models for outdoor } \\
\text { machine vision.(2001) }\end{array}$ & $\begin{array}{l}\text { Here shape-based recognition is } \\
\text { efficient and accurate by using } \\
\text { histogram equalization method. }\end{array}$ & $\begin{array}{c}\text { For better accuracy, we we } \\
\text { can use it in future. }\end{array}$ \\
\hline $\begin{array}{l}\text { Ulzii-Orshikh Dorj et al. have } \\
\text { represented a comparative study on } \\
\text { tangerine detection, counting and } \\
\text { yield estimation algorithm.(2013) }\end{array}$ & $\begin{array}{l}\text { For better perform histogram of } \\
\text { colour component Cb in YCbCr, and } \\
\text { thresholding in Cb has used. }\end{array}$ & $\begin{array}{l}\text { For extracting colour } \\
\text { component we can use the } \\
\text { method. }\end{array}$ \\
\hline $\begin{array}{l}\text { Minjun Wang et al. have } \\
\text { proposed a novel algorithm for green } \\
\text { circuits detection based on reticulate } \\
\text { gray ladder feature.(2016) }\end{array}$ & $\begin{array}{l}\text { In this case, an 8-gray label image } \\
\text { was generated by the pre-processing } \\
\text { step of median filter, histogram based } \\
\text { system. }\end{array}$ & $\begin{array}{l}\text { In this case connectivity } \\
\text { component was a major } \\
\text { aspect. }\end{array}$ \\
\hline
\end{tabular}

A histogram shows history representation of distribution of numerical data. It is an estimate of the probability distribution of continuous variable. D. S. Jayas et al. ${ }^{[7]}$ have described multi-layer neural networks for image analysis of agricultural products. In this case, the histogram of these pixels shows the brightness distribution found in the object. The mean brightness represents the average brightness of an object. Libin Zhang et al. ${ }^{[8]}$ have proposed recognition of greenhouse cucumber fruit using computer vision. In this case, some descriptors of texture based on the intensity histogram were obtained such as mean, standard deviation, smoothness \& third moment. By comparison, the "third moment" was the most effective parameter for upper part determination. Zania S Pothen et al. ${ }^{[9]}$ have proposed texture-based fruit detection using the smooth patterns of fruit images. Candidate fruit locations that has passed to the initial filter are classified using modified histogram of oriented gradients combined with a pairwise intensity comparison texture descriptor and random forest classifier. Here overall F1 accuracy score of 0.82 for grapes and 0.80 for apples. Palaniappan Annamalai, et al. ${ }^{[10]}$ have proposed citrus yield mapping system using machine vision. In this paper images of the citrus fruits were analysed by using histogram \& pixel distributions of various classes (citrus, leaf, and background) were developed. The algorithm was tested on 59 validation images and the R2 value between the number of fruits counted by the machine vision algorithm and the average number of fruits by manual counting was 0.76 . Annamalai, et al. $\left.{ }^{[11}\right]$ have described papaya size grading using central profile analysis of the digital image. Otsu's method for automatic threshold selection from a histogram of the image was successfully applied to various segmentation cases. This method is based on selecting the lowest point between two classes of the histogram by using class variance. Q. M. Jonathan $\mathrm{Wu}$ et al ${ }^{\left[{ }^{[2]}\right]}$ have proposed a fruit recognition method for automatic harvesting. Here shape-based recognition is efficient and reliable by using depth histogram representation. The first step is to derive depth histograms of objects of interest. The statistical distribution of the depth histogram of targeted fruit can be used to characterize the shape of target objects. Sashi. D.Buluswar et al. ${ }^{[13]}$ have proposed colour models for outdoor machine vision. The points for each of the point represent two linear cluster histogram which together forms a dichromatic plot. Ulzii-Orshikh Dorj et al. ${ }^{[14]}$ have described a comparative analysis on tangerine fruits detection, counting by using yield estimation algorithm. Removal of noise and counting methods are used and executed to perform counting algorithm. For better performance histogram of colour component $\mathrm{Cb}$ in $\mathrm{YCbCr}$ and thresholding in $\mathrm{Cb}$ component has used. Minjun Wang et al. ${ }^{[15]}$ have proposed a novel algorithm for green circuits detection based on reticulate gray ladder feature. In this case, an 8-gray label image was generated by the pre-processing step of median filter, histogram based system (Table 2). 


\section{HSI Technique}

Table 3

\begin{tabular}{|c|c|c|}
\hline \multicolumn{3}{|c|}{ Analysis of Algorithm Related to HSI Technique } \\
\hline Authors \& Years & Goals & $\begin{array}{c}\text { Future } \\
\text { Prospective }\end{array}$ \\
\hline $\begin{array}{l}\text { Alireza Khoshroo et al. have } \\
\text { proposed detection of red tomato } \\
\text { on plants using image } \\
\text { processing techniques.(2014) }\end{array}$ & $\begin{array}{l}\text { HSI (hue, saturation and intensity) space is } \\
\text { known as one of the most powerful colour spaces. } \\
\text { This method has developed based on the concept } \\
\text { of visual perception in human eyes. }\end{array}$ & $\begin{array}{l}\text { This technique will } \\
\text { very useful in various } \\
\text { detection parts of } \\
\text { fruits and vegetables. }\end{array}$ \\
\hline $\begin{array}{l}\text { A.R. JimeHnez et al. have } \\
\text { developed automatic fruit } \\
\text { recognition by image processing } \\
\text { system.(2010) }\end{array}$ & $\begin{array}{l}\text { Vision system used for this project is based on a } \\
\text { colour camera that supplies the HSI colour } \\
\text { components. Hue and Saturation histograms are } \\
\text { employed to perform a thresholding to segment the } \\
\text { image. }\end{array}$ & $\begin{array}{l}\text { This technique will } \\
\text { very useful in the } \\
\text { segmentation process. }\end{array}$ \\
\hline $\begin{array}{l}\text { Narendra V G et al. have } \\
\text { proposed quality analysis of } \\
\text { agricultural food products by } \\
\text { computer vision method.(2010) }\end{array}$ & $\begin{array}{l}\text { Apple images were performed for the purpose } \\
\text { of classification into yellow or green groups using } \\
\text { the HSI (hue, saturation, intensity) colour system } \\
\text { method. }\end{array}$ & \begin{tabular}{lr}
\multicolumn{2}{c}{ For classification of } \\
various fruits and \\
vegetables, \\
method will use.
\end{tabular} \\
\hline $\begin{array}{l}\text { Tadhg Brosnan et al. have } \\
\text { proposed analysis and grading of } \\
\text { agricultural products by machine } \\
\text { vision .(2003) }\end{array}$ & This results in an accuracy of $90 \%$. & $\begin{array}{l}\text { This method will } \\
\text { use any kind of fruits } \\
\text { for better results. }\end{array}$ \\
\hline
\end{tabular}

Alireza Khoshroo et al. ${ }^{[16]}$ have proposed detection of red tomato on plants using image processing techniques. Colour space transformation is a powerful tool for colour feature extraction. HSI (hue, saturation, and intensity) space is known as one of the most powerful colour spaces. HSI space is developed based on the concept of visual perception in human eyes; therefore their colour measurements have a better relationship with visual significance of fruit surfaces. Results obtained from testing the developed algorithm showed an encouraging accuracy $(82.38 \%)$ to develop an expert system for online recognition of red tomatoes. A.R. JimeHnez et al. ${ }^{[17]}$ have developed automatic fruit recognition using pattern recognition methods. Vision system used for this project is based on a colour camera that supplies the HSI colour components. Hue and Saturation histograms are employed to perform a thresholding to segment the image. The three-dimensional information is obtained by a stereo matching of two different images of the same scene. About $90 \%$ of the ripe tomatoes are detected and the most frequent errors are due to occlusions. Narendra V G et al. ${ }^{[18]}$ have proposed quality analysis of agricultural food products by computer vision method. Fruits of apple image were taken and performed for the purpose of identification into yellow or green groups using HSI (hue, saturation, intensity) colour model. The result of accuracy was $95 \%$. Tadhg Brosnan et al. ${ }^{[19]}$ have proposed quantify and grading of agricultural products by machine vision systems. The results show that an accuracy of over $90 \%$ (Table 3 ).

\section{Colour-Mapping Technique}

J.C. Noordam et al ${ }^{[20]}$ have proposed high-speed potato grading and quality inspection based on a colour vision system. The colour segmentation technique uses linear discriminate analysis (LDA) in addition with the Mahalanobis distance classifier to classify the pixels. Basically Mahalanobis distance is the distance between any point P and a distribution D. This method was introduced by P. C. Mahalanobis in 1936. Krishna Kumar Patel et al. ${ }^{[21]}$ have proposed machine vision system: a tool for quality inspection of food and agricultural products. At the current stage, the quality has been assessed traditionally by hand inspecting the products individually or sampling large batches which is time consumeing and unreliable in nature. C. S. Nandi et al. ${ }^{[22]}$ have described machine vision based techniques for automatic mango fruit sorting and grading based on maturity level and size. Colour vision systems have been developed for agricultural grading applications which include direct colour mapping system to evaluate the quality of tomatoes. Ms. Rupali et al. ${ }^{[23]}$ have proposed a fruit quality management system based on image processing. This paper presents a fruit size detecting and grading system based on image processing. The early assessment of fruit quality requires new tools for size and colour measurement. The side view images of fruits have captured. After that some fruit characters have extracted by using detecting algorithms. K. Parvati et al. ${ }^{[24]}$ have proposed image segmentation using gray-scale morphology and marker-controlled watershed transformation. Segmentation, a new method, for colour, grayscale MR medical images, and aerial images, has proposed. Edge detection algorithm includes function edge and marker-controlled watershed segmentation. Miss. Anuradha Gawande et al. ${ }^{[25]}$ have described implementation of fruits grading and sorting system by using image processing and data classifier. Texture, 
PCA, pattern classification etc. methods are used. S.Arivazhagan et al. ${ }^{[26]}$ have proposed fruit recognition using colour \& texture features. Machine vision techniques used to detect a fruit rely having four basic features, which characterize the object's intensity, colour, shape and texture properties. This research work approaches an efficient mixture of colour \& texture features for fruit recognition. D. Surya Prabha et al. ${ }^{[27]}$ have proposed assessment of banana fruit maturity by image processing technique. This analysis has attempted to use image processing methods to detect the maturity stage of fresh banana fruit by its colour and size value of their images precisely. In the respective work, a total of 120 images comprising 40 images from each stage such as undermature, mature and over-mature were used for developing algorithm and accuracy prediction. Devrim Unay et al. ${ }^{[28]}$ have developed thresholding-based segmentation and apple grading by machine vision. M.Z. Abdullah, et al., ${ }^{[29]}$ proposed discrimination and classification of fresh-cut star fruits (Averrhoa carambola L.) using automated machine vision system (Table 4).

Table 4

\begin{tabular}{|c|c|c|}
\hline \multicolumn{3}{|c|}{ Analysis of Algorithm Related to Colour-Mapping Technique } \\
\hline Author \& Years & Goals & Future prospective \\
\hline $\begin{array}{l}\text { J.C. Noordam et al. have proposed } \\
\text { high-speed potato grading and quality } \\
\text { inspection based on a colour vision } \\
\text { system.(2014) }\end{array}$ & $\begin{array}{l}\text { The colour segmentation procedure } \\
\text { uses linear discriminate analysis (LDA) } \\
\text { in combination with a Mahalanobis } \\
\text { distance classifier to classify the pixels. }\end{array}$ & $\begin{array}{l}\text { This technique will } \\
\text { further use in any type of } \\
\text { segmentation process. }\end{array}$ \\
\hline $\begin{array}{l}\text { Patel et al. have proposed machine } \\
\text { vision system: a tool for quality } \\
\text { inspection of food and agricultural } \\
\text { products.(2012) }\end{array}$ & $\begin{array}{l}\text { The colour mapping technique has } \\
\text { used for quality assessment of the food. }\end{array}$ & $\begin{array}{l}\text { This will further use in } \\
\text { any type of vegetable } \\
\text { quality analysis. }\end{array}$ \\
\hline $\begin{array}{l}\text { C. S. Nandi et al. have described } \\
\text { machine vision based techniques for } \\
\text { automatic mango fruit sorting and } \\
\text { grading based on maturity level and } \\
\text { size.(2013) }\end{array}$ & $\begin{array}{l}\text { Colour vision systems have been } \\
\text { developed for agricultural grading } \\
\text { applications which include direct } \\
\text { colour mapping system to evaluate the } \\
\text { quality of tomatoes and dates. }\end{array}$ & $\begin{array}{l}\text { For quality analysis of } \\
\text { vegetable, this method will } \\
\text { use. }\end{array}$ \\
\hline $\begin{array}{l}\text { Ms.Rupali et al. have proposed a } \\
\text { fruit quality management system based } \\
\text { on image processing. }(2013)\end{array}$ & $\begin{array}{l}\text { For fruit detection and analysis this } \\
\text { method has used. }\end{array}$ & $\begin{array}{l}\text { In future also this } \\
\text { technique will use. }\end{array}$ \\
\hline $\begin{array}{l}\text { K. Parvati, et al. have proposed } \\
\text { image segmentation using gray-scale } \\
\text { morphology and marker-controlled } \\
\text { watershed transformation.(2008) }\end{array}$ & $\begin{array}{l}\text { Segmentation, a new method, for } \\
\text { colour, gray-scale MR medical images, } \\
\text { and aerial images, has proposed. }\end{array}$ & $\begin{array}{l}\text { This method will use in } \\
\text { segmentation for any kind } \\
\text { of objects. }\end{array}$ \\
\hline $\begin{array}{l}\text { Miss. Anuradha Gawande et al. have } \\
\text { described implementation of fruits } \\
\text { grading and sorting system by using } \\
\text { image processing and data } \\
\text { classifier.(2015) }\end{array}$ & $\begin{array}{l}\text { Classification of fruits has also used } \\
\text { color-based method. }\end{array}$ & $\begin{array}{l}\text { This process will have } \\
\text { various future aspects. }\end{array}$ \\
\hline $\begin{array}{l}\text { S.Arivazhagan et al. have proposed } \\
\text { fruit recognition using colour and } \\
\text { texture features.(2010) }\end{array}$ & $\begin{array}{l}\text { Colour based segmentation has the } \\
\text { major aspect of this technique. }\end{array}$ & $\begin{array}{l}\text { Colour } \quad \text { based } \\
\text { segmentation will use for } \\
\text { detection of objects. }\end{array}$ \\
\hline $\begin{array}{l}\text { D. Surya Prabha et al. have proposed } \\
\text { assessment of banana fruit maturity by } \\
\text { image processing technique. (2013) }\end{array}$ & $\begin{array}{l}\text { The study attempted to use image } \\
\text { processing technique to detect the } \\
\text { maturity stage of fresh banana fruit by } \\
\text { its colour and size value of their } \\
\text { images precisely. }\end{array}$ & $\begin{array}{l}\text { The various technique } \\
\text { will use in various aspects. }\end{array}$ \\
\hline $\begin{array}{l}\text { Devrim Unay et al. have developed } \\
\text { thresholding-based segmentation and } \\
\text { apple grading by machine } \\
\text { vision.(2010) }\end{array}$ & $\begin{array}{l}\text { In order to segment defects, Lemans } \\
\text { et al. introduced a Gaussian model of } \\
\text { skin colour for 'Golden Delicious'. }\end{array}$ & $\begin{array}{l}\text { Future aspect of this } \\
\text { method wills detection of } \\
\text { skin diseases and other } \\
\text { diseases also possible. }\end{array}$ \\
\hline $\begin{array}{l}\text { M.Z. Abdullah et al. have proposed } \\
\text { discrimination and classification of } \\
\text { fresh-cut star fruits (Averrhoa } \\
\text { carambola L.) using automated } \\
\text { machine vision system. (2005) }\end{array}$ & $\begin{array}{l}\text { The color based technique will } \\
\text { major aspects. }\end{array}$ & $\begin{array}{l}\text { This method will give } \\
\text { better accuracy in all the } \\
\text { cases. }\end{array}$ \\
\hline
\end{tabular}




\section{E. RGB Color Space Method}

Narendra V G et al. ${ }^{[30]}$ have proposed quality analysis of agricultural fruits by using computer vision method. In this research work, it has used automated grading system for oil palm fruits using RGB color model. The grading technique was used to distinguish between the three different categories of oil palm fruit bunches. Krishna Kumar Patel et al. ${ }^{[31]}$ have proposed machine vision system: a tool for quality inspection of food and agricultural products. It was developed an automated grading system for oil palm bunches using the RGB color model to distinguish between the three different categories of oil palm fruit bunches. In their study, the result showed that the ripeness of fruit bunch could be differentiated between different categories of fruit bunches based on RGB intensity. Van Huy Pham et al. ${ }^{[32]}$ have proposed an image segmentation approach for fruit defect detection using k-means clustering and graph-based algorithm. It was used different threshold values for color channels in RGB space to distinguish different varieties of objects of interest and the background. Haisheng GAO et al. ${ }^{[33]}$ have proposed automatic grading of the post-harvest fruit. RGB and HSI model were often used in computer vision system to describe the color, which is more similar to the manner of human vision. The HSI model includes three elements: hue, saturation and intensity. Mathew George, et al. ${ }^{[34]}$ have proposed multiple fruit and vegetable sorting system using machine vision. The image transferred into the form of Red, Green and Blue (RGB) color model by using Matlab. This model uses the combination of all the three components for creating a color. The segmentation using this particular model is less efficient as lighting, reflection and other factors disrupt the different and hence consistent segmentation cannot be achieved. Sakya Sarkar et al. ${ }^{[35]}$ have proposed a comprehensive approach for fruit pattern recognition under the framework of digital image processing. The pioneer researchers have presented in their approach a Matlab based RGB model of image recognition technique. Classifies and identifies fruits successfully up to $90 \%$ accuracy. This system is also useful tool in a variety of fields such as educational, image retrieval and plantation science. Jagadeesh D.Pujari et al. ${ }^{[36]}$ have proposed recognition and classification of normal and affected agricultural product using reduced color and texture features. A new model of grading system for oil palm fruit has developed using the RGB color model and fuzzy logic. Machine vision techniques has developed for the image processing parts like the segmentation of colors, calculation of mean color intensity based on RGB color technique and the decision making process using fuzzy logic is used to train the data and make the classification for the oil palm fruit. The average accuracies of classification have increased to $88.28 \%$ and $83.80 \%$ for normal and affected agricultural product respectively. H.N Patel et al. ${ }^{[37]}$ have proposed automatic segmentation and measurement of fruit using shape analysis. Color and shape analysis was used to segment the images of different fruits like apple, pomegranate, oranges, peach and plum obtained by any conventional camera. At first the input section tree image was converted from RGB into $\mathrm{L}^{*} \mathrm{a} * \mathrm{~b}$ color space. The results show that the proposed method can accurately segment the fruits having accuracy of $98 \%$ and the average measurement error was found as $31.4 \%$ (Table 4 ).

Table 5

\begin{tabular}{|c|c|c|c|}
\hline \multicolumn{3}{|c|}{ Analysis of Algorithm Related to RGB COLOR SPACE Method } & \multicolumn{1}{|c|}{ Goals } \\
\hline \multicolumn{1}{|c|}{ Author \& Years } & \multicolumn{1}{|c|}{ Future Prospective } \\
\hline $\begin{array}{l}\text { Narendra V G et al. have proposed } \\
\text { quality inspection and grading of } \\
\text { agricultural and food products by } \\
\text { computer vision- a review.(2010) }\end{array}$ & $\begin{array}{c}\text { This paper has proposed an automated } \\
\text { grading system for oil palm bunches using } \\
\text { the RGB colour model. }\end{array}$ & $\begin{array}{c}\text { RGB colour model can } \\
\text { use in quality analysis of } \\
\text { fruits. }\end{array}$ \\
\hline $\begin{array}{l}\text { Krishna Kumar Patel et al. have } \\
\text { proposed machine vision system: a tool } \\
\text { for quality inspection of food and } \\
\text { agricultural products.(2011) }\end{array}$ & $\begin{array}{l}\text { It was developed an automated grading } \\
\text { system for oil palm bunches using the } \\
\text { RGB colour model to distinguish between } \\
\text { the three different categories of oil palm } \\
\text { fruit bunches. }\end{array}$ & $\begin{array}{c}\text { For grading purpose, it } \\
\text { is a very useful method. }\end{array}$ \\
\hline $\begin{array}{l}\text { Van Huy Pham et al. have proposed an } \\
\text { image segmentation approach for fruit } \\
\text { defect detection using k-means clustering } \\
\text { and graph-based algorithm.(2014) }\end{array}$ & $\begin{array}{l}\text { It was used different thresholds for } \\
\text { colour channels in RGB colour space to } \\
\text { separate different categories of objects of } \\
\text { interest and the background. }\end{array}$ & $\begin{array}{l}\text { By using a threshold } \\
\text { value this method will } \\
\text { give an accurate result. }\end{array}$ \\
\hline $\begin{array}{l}\text { Haisheng GAO et al. have proposed } \\
\text { automatic grading of the post-harvest } \\
\text { fruit.(2010) }\end{array}$ & $\begin{array}{l}\text { RGB and HSI model were often used in } \\
\text { computer vision system to describe the } \\
\text { color, which is more similar to the manner } \\
\text { of human vision. }\end{array}$ & $\begin{array}{l}\text { The RGB model will } \\
\text { often use in computer } \\
\text { vision analysis. }\end{array}$ \\
\hline $\begin{array}{l}\text { George et al. have proposed multiple } \\
\text { fruit and vegetable sorting system using } \\
\text { machine vision.(2015) }\end{array}$ & $\begin{array}{l}\text { The image transferred into Matlab is in } \\
\text { the form of Red, Green and Blue (RGB) } \\
\text { colour model. This model uses the } \\
\text { combination all the three components for } \\
\text { creating a colour. }\end{array}$ & $\begin{array}{l}\text { The RGB model will be } \\
\text { very useful in the } \\
\text { segmentation process. }\end{array}$ \\
\hline
\end{tabular}




\begin{tabular}{|l|l|c|}
\hline $\begin{array}{l}\text { Sakya Sarkar et al. have proposed a } \\
\text { comprehensive approach for fruit pattern } \\
\text { recognition under the framework of } \\
\text { digital image processing.(2014) }\end{array}$ & $\begin{array}{l}\text { The pioneer researchers have presented } \\
\text { in their approach a Matlab based RGB } \\
\text { model of Image recognition technique. }\end{array}$ & $\begin{array}{l}\text { Matlab based RGB } \\
\text { model will use in } \\
\text { recognition technique. }\end{array}$ \\
\hline $\begin{array}{l}\text { Jagadeesh D.Pujari et al. have proposed } \\
\text { recognition and classification of normal } \\
\text { and affected agriculture produce using } \\
\text { reduced colour and texture } \\
\text { features.(2014) }\end{array}$ & $\begin{array}{l}\text { The computer program is developed for } \\
\text { the image processing part like the } \\
\text { segmentation of colours, calculation of } \\
\text { mean colour intensity based on RGB } \\
\text { colour model and the decision-making } \\
\text { process using fuzzy logic to train the data } \\
\text { and make the classification for the oil palm } \\
\text { fruit. }\end{array}$ & $\begin{array}{c}\text { For better segmentation } \\
\text { analysis we will use RGB } \\
\text { colour space method. }\end{array}$ \\
\hline $\begin{array}{l}\text { H.N Patel et al. proposed have } \\
\text { automatic segmentation and yield } \\
\text { measurement of fruit using shape } \\
\text { analysis.(2012) }\end{array}$ & $\begin{array}{l}\text { At first the input section tree image was } \\
\text { converted from RGB into L*a*b colour } \\
\text { space. The results indicate that the } \\
\text { proposed method can accurately segment } \\
\text { the fruits having efficiency of 98\% and the } \\
\text { average measurement error was found as } \\
31.4 \% .\end{array}$ & $\begin{array}{l}\text { It will helpful in any } \\
\text { analysis. }\end{array}$ \\
\end{tabular}

\section{III.CLASSIFICATION TECHNIQUE}

\section{F. Support Vector Machine}

Support Vector Machines (SVMs) are a supervised learning technique widely used for many different kinds of classification tasks. They were initially conceived to solve classification problems between only two classes, but they can be employed in multiclass problems by using one-against-all or one-against-one techniques. In machine learning method, support vector machines (SVMs, also support vector networks) are consist of learning algorithms that analyse data and identify patterns, used for classification and analysis (Figure 2).

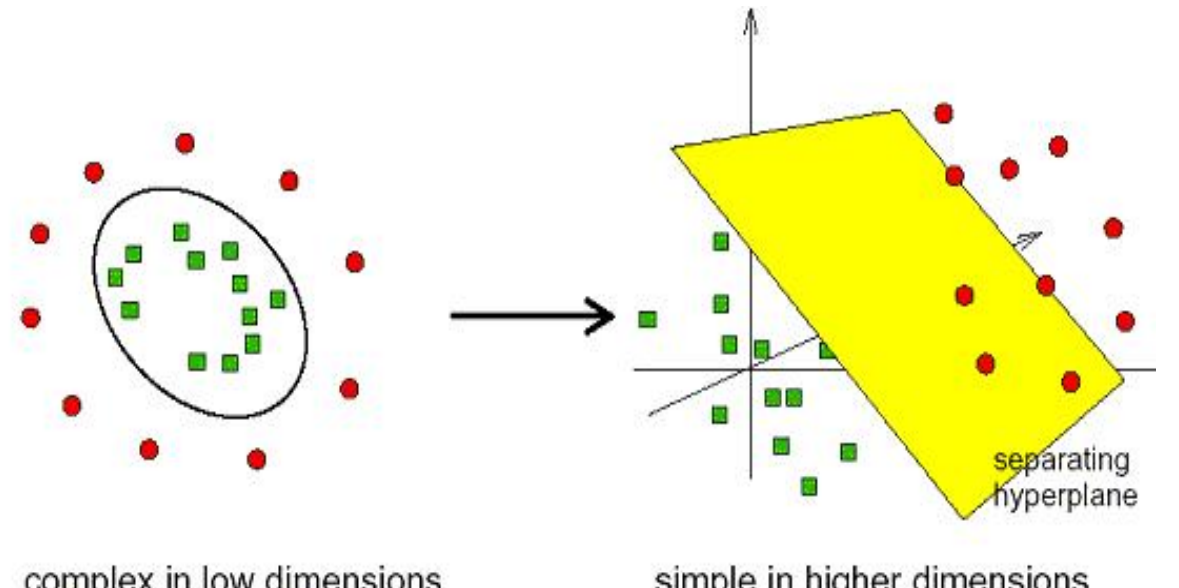

Figure 2 Principle of Support vector machine 
Table 6

\begin{tabular}{|c|l|c|}
\hline \multicolumn{4}{|c|}{ Analysis of Algorithm Related to Support Vector Machine } & \multicolumn{1}{|c|}{ Future prospective } \\
\hline \multicolumn{1}{|c|}{ Author \& Years } & \multicolumn{1}{|c|}{ Goals } & PVM will give the exact \\
$\begin{array}{l}\text { W.S. Qureshi, et al. have } \\
\text { proposed machine vision for } \\
\text { counting fruit on mango tree } \\
\text { canopies. (2014) }\end{array}$ & $\begin{array}{l}\text { Pixel classification based on super- } \\
\text { pixel over-segmentation, clustering of } \\
\text { dense SIFTS features into visual words } \\
\text { and bag-of-visual-word super-pixel } \\
\text { classification using SVMs (support } \\
\text { vector machine). }\end{array}$ & $\begin{array}{l}\text { SVM } \\
\text { result of any research. }\end{array}$ \\
\hline $\begin{array}{l}\text { Shuiguang Deng, et al., have } \\
\text { proposed a feature-selection } \\
\text { algorithm based on support vector } \\
\text { machine-multiclass for hyper } \\
\text { spectral visible spectral } \\
\text { analysis.(2013) }\end{array}$ & $\begin{array}{l}\text { This article proposes a novel feature } \\
\text { selection algorithm named (SVM- }\end{array}$ & $\begin{array}{c}\text { This method will have very } \\
\text { broad future prospective. }\end{array}$ \\
\hline
\end{tabular}

W.S. Qureshi et al. ${ }^{[38]}$ have proposed machine vision for counting fruits on mango tree canopies. Pixel based classification on super-pixel over-segmentation, clustering of dense SIFTS features into visual words and bagof-visual-word super-pixel classification using SVMs (support vector machine) etc methods have used. Shuiguang Deng et al. ${ }^{[39]}$ have proposed a feature-selection algorithm based on support vector machinemulticlass for hyper spectral analysis. This article has proposed a novel feature selection algorithm named support vector machine-multiclass forward feature selection (SVM-MFFS). SVM-MFFS adopts the wrapper and forward feature selection strategy, explores the stability of spectral variables, and uses classical SVM as classification and regression model to select the most relevant wavelengths from hundreds of spectral data. They compare SVM-MFFS with successive projection analysis and uninformative variable elimination in the experiment of identifying different brands of oil. The results show that SVM-MFFS outperforms in accuracy, receiver operating characteristic curve, prediction and cumulative stability, and it will provide a reliable and rapid method in food quality inspection (Table 6).

G. K-Nearest Neighbors Classifier (KNN)

Table 7

\begin{tabular}{|c|c|c|}
\hline \multicolumn{3}{|c|}{ Analysis of Algorithm Related to K-Nearest Neighbours Classifier (KNN) } \\
\hline Author \& Years & Goals & $\begin{array}{c}\text { Future } \\
\text { Prospective }\end{array}$ \\
\hline $\begin{array}{l}\text { Woo Chaw Seng et al. have proposed } \\
\text { a new method for fruits recognition } \\
\text { system.(2013) }\end{array}$ & $\begin{array}{l}\text { For fruits recognition system, the KNN } \\
\text { algorithm performs fruit classification by } \\
\text { using the distance measure, which is the } \\
\text { Euclidean distance metric to measure the } \\
\text { distance between the attributes of the } \\
\text { unknown fruit with the stored fruit. }\end{array}$ & $\begin{array}{l}\text { KNN will very } \\
\text { much use in future } \\
\text { prospective. }\end{array}$ \\
\hline $\begin{array}{l}\text { Miss. Anuradha Gawande et al. have } \\
\text { proposed Implementation of fruits } \\
\text { grading and sorting system by using } \\
\text { image processing and data } \\
\text { classifier.(2015) }\end{array}$ & $\begin{array}{l}\text { The defected area from fruit images and } \\
\text { grading them as per their level of infection } \\
\text { and by using KNN classifier. }\end{array}$ & $\begin{array}{l}\text { KNN will be also } \\
\text { used in vegetables } \\
\text { grading purpose. }\end{array}$ \\
\hline
\end{tabular}

Woo Chaw Seng et al. ${ }^{[40]}$ have proposed a new method for fruits recognition system. This section outlines the methodology and data that are used to develop the fruit recognition system, and presents the pseudo-code for the developed system. For fruits recognition system, the KNN algorithm performs fruit classification by using the distance measure, which is the Euclidean distance metric to measure the distance between the attributes of the unknown fruit with the stored fruit. Proposed fruit recognition system analyses and identifies fruits successfully up to $90 \%$ accuracy. This system also serves as a useful tool in a variety fields such as educational, image retrieval and plantation science. Miss. Anuradha Gawande et al. ${ }^{[41]}$ have proposed implementation of fruits grading and sorting system by using image processing and data classifier. Experimental results suggest that the proposed approach have the ability to find out the defected area from fruit images and grading them as per their level of infection using KNN classifier. It can accurately classify the infected images and store in their respective database (Table 7). 


\section{H. Artificial Neural Network}

Recently neural networks method has become very popular, which is used to characterize biological processes. It has best decision-making capability which can be used in image analysis of biological products, where the size and shape classification is not achieved by any mathematical function. When it is combined with hightechnology handling systems, it gives consistent performance, which is the most important benefit of these artificial classifiers in classification of agricultural products. These networks are based on the concept of the biological nervous system, and have proved to be robust in dealing with the ambiguous data and the kind of problems that require the interpolation of large amounts of data (Figure 3).

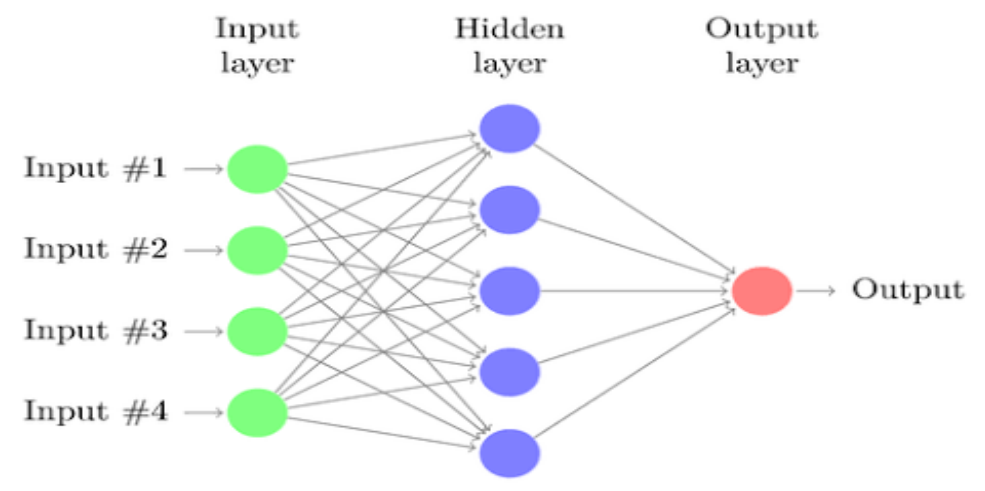

Figure 3 Multi layered artificial network

Peilin Li et al. ${ }^{[42]}$ have proposed study on citrus fruit image data separability by segmentation methods. Artificial neural network (ANN) and decision theoretic classifier were used for the segmentation of apples image for the harvesting robot. Both methods achieved $80 \%$ fruits detected. Jagadeesh Devdas Pujari et al. ${ }^{[43]}$ have proposed quality analysis and classification of anthracnose fungal disease of fruits based on statistical texture features. These features are then used for classification purpose using ANN classifier. They conducted experimentation on a dataset of 600 fruits' image samples. The accuracies of classification of normal and affected fruit types are $84.65 \%$ and $76.6 \%$ respectively. This work finds application in developing machine vision technique in the horticulture field. Gurea Tonguc et al. ${ }^{[4]}$ have proposed fruit grading using image processing technique. All this work is supported by ANN and some custom programming method. Uravashi Solanki et al. ${ }^{[45]}$ have proposed detection of disease and fruit grading. The classifier is used for classifying images based on their features. There are many classifiers are available. Naive bays classifier, K-Nearest neighbours (K-NN), support vector machine (SVM), artificial neural network (ANN) and random forest tree classifier. The respective paper has presented identification of different features of fruits, a different classifier for diseases detection and different fruit segmentation technique for fruit quality analysis (Table ).

Table 8

\begin{tabular}{|c|c|c|}
\hline \multicolumn{3}{|c|}{ Analysis of Algorithm Related to Artificial Neural Network } \\
\hline \multicolumn{1}{|c|}{ Author \& Years } & \multicolumn{1}{c|}{ Goals } & \multicolumn{1}{c|}{ Future Prospective } \\
\hline $\begin{array}{c}\text { Peilin Li et al. have proposed } \\
\text { study on citrus fruit image data } \\
\text { separability by segmentation } \\
\text { methods.(2011) }\end{array}$ & $\begin{array}{l}\text { Artificial neural network (ANN) and } \\
\text { decision theoretic classifier were used for } \\
\text { the segmentation of apples in the image for } \\
\text { the harvesting robot. }\end{array}$ & $\begin{array}{l}\text { ANN will be used in the } \\
\text { future analysis of any } \\
\text { system }\end{array}$ \\
\hline $\begin{array}{l}\text { Jagadeesh Devdas Pujari et al. } \\
\text { have proposed grading and } \\
\text { classification of anthracnose } \\
\text { fungal disease of fruits based on } \\
\text { statistical texture features.(2013) }\end{array}$ & $\begin{array}{c}\text { These features are then used for } \\
\text { classification purpose using ANN classifier. }\end{array}$ & $\begin{array}{l}\text { ANN will be also used in } \\
\text { anype of classification } \\
\text { for any objects. }\end{array}$ \\
\hline $\begin{array}{l}\text { Gurea Tonguc et al. have } \\
\text { proposed fruit grading using } \\
\text { image processing } \\
\text { technique.(2009) }\end{array}$ & $\begin{array}{l}\text { All this work is supported by ANN and } \\
\text { some custom programming method is } \\
\text { possible to certain the decision } \\
\text { programming method. }\end{array}$ & $\begin{array}{l}\text { This ANN method will } \\
\text { used } \\
\text { programming method. } \\
\text { custom }\end{array}$ \\
$\begin{array}{l}\text { Solanki et al. have proposed a } \\
\text { survey on detection of disease and } \\
\text { fruit grading.(2015) }\end{array}$ & $\begin{array}{l}\text { Artificial neural network (ANN) and random } \\
\text { forest tree classifier. This paper presented } \\
\text { different features of fruits, a different classifier } \\
\text { for diseases detection and different fruit } \\
\text { segmentation technique for fruit grading. }\end{array}$ & \\
\hline
\end{tabular}




\section{Fuzzy Logic Technique}

Fuzzy logic has been used in a wide range of problem domains. Applications area of fuzzy logic is very wide: process control, management \& decision making, operations research, economics, pattern recognition and classification. FL is used to handle uncertainty, ambiguity and vagueness. Once the features are fixed, they are led in input to a classifier which outputs a value associated to the classification of the quality (integer value) or a quality index (real value). The classification can be divided into two approaches: conventional classification and computational intelligence-based classification. ". Fuzzy Logic provides a structure to model uncertainty, the human way of reasoning and the perception process. Fuzzy Logic is based on natural language and through a set of rules an inference system is built which is the basis of the fuzzy computation (Figure 4).

\section{FUZZY INFERENCE SYSTEM}

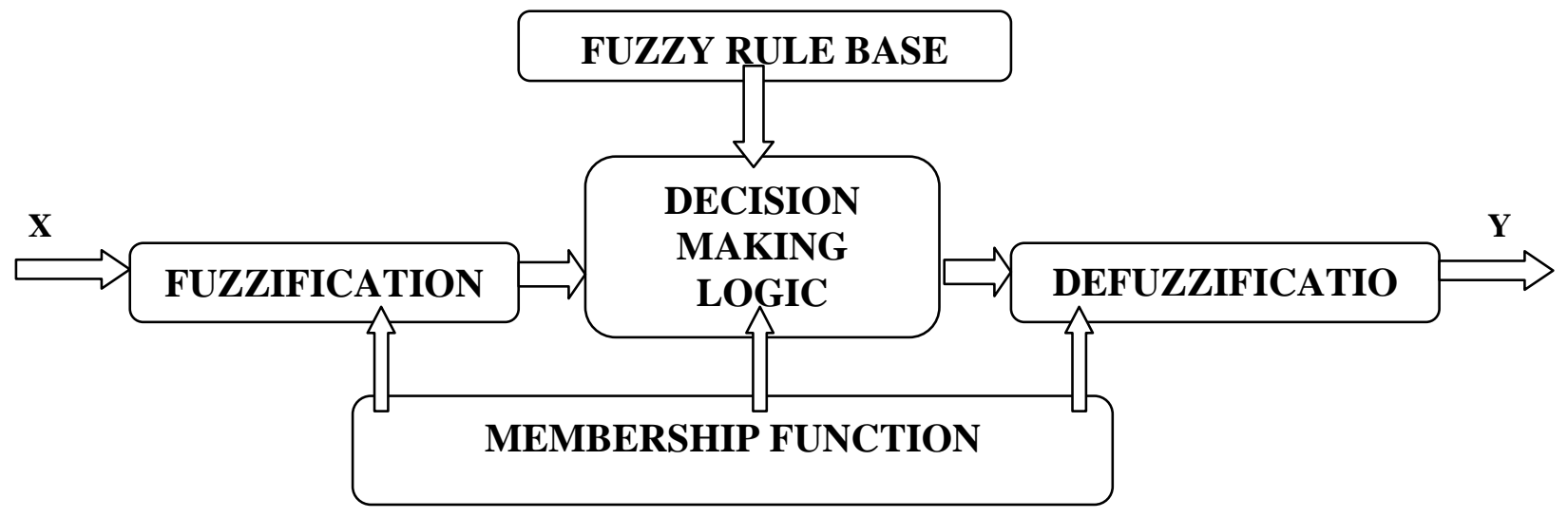

Figure 4 Fuzzy logic concept

Jagadeesh D.Pujari et al. ${ }^{[46]}$ have proposed recognition and classification of normal and affected agriculture produce using reduced colour and texture features. This paper has developed a new model of automated grading system for oil palm fruit is developed using the RGB colour model and artificial fuzzy logic. The average classification accuracies have $88.28 \%$ respectively. Queerzzs akeemu amin et al. ${ }^{[47]}$ have proposed Image processing for quality and safety control in horticultural industries. In this paper, an automatic classification method of tobacco leaves based on the digital image processing and the fuzzy sets theory is presented. A grading system based on image processing techniques was developed for automatically inspecting flue-cured tobacco leaves. Jagadeesh Devdas Pujari et al. ${ }^{[48]}$ have proposed grading and classification of anthracnose fungal disease of fruits based on statistical texture features. It has developed a new model of automated grading system for oil palm fruit is developed using the RGB colour model and artificial fuzzy logic. The classification accuracies for intact and affected anthracnose fruit types are $84.65 \%$ and $76.6 \%$ respectively. D. S. Gaikwad et al. ${ }^{[49]}$ have proposed image processing approach for grading and identification of diseases on pomegranate fruit.

Table 9

\begin{tabular}{|c|c|c|}
\hline \multicolumn{5}{|c|}{ Analysis of Algorithm Related to Fuzzy Logic Technique } \\
\hline \multicolumn{1}{|c|}{ Author \& Years } & \multicolumn{1}{|c|}{ Goals } & Future Prospective \\
\hline $\begin{array}{l}\text { Jagadeesh D.Pujari et al. have proposed } \\
\text { recognition and classification of normal } \\
\text { and affected agriculture produce using } \\
\text { reduced colour and texture features. } \\
(2015)\end{array}$ & $\begin{array}{l}\text { This paper has developed a new } \\
\text { model of automated grading system for } \\
\text { oil palm fruit is developed using the } \\
\text { RGB colour model and artificial fuzzy } \\
\text { logic. }\end{array}$ & $\begin{array}{c}\text { For automated } \\
\text { grading system, this } \\
\text { method will use. }\end{array}$ \\
\hline $\begin{array}{l}\text { Queerzzs akeemu amin et al. have } \\
\text { proposed Image processing for quality and } \\
\text { safety control in Horticultural } \\
\text { Industries.(2014) }\end{array}$ & $\begin{array}{l}\text { In this paper, an automatic } \\
\text { classification method of tobacco leaves } \\
\text { based on the digital image processing } \\
\text { and the fuzzy sets theory is presented. }\end{array}$ & $\begin{array}{l}\text { This method will } \\
\text { further use in any types } \\
\text { of leaves. }\end{array}$ \\
\hline $\begin{array}{l}\text { Jagadeesh Devdas Pujari et al. have } \\
\text { proposed grading and classification of } \\
\text { anthracnose fungal disease of fruits based } \\
\text { on statistical texture features. (2009) }\end{array}$ & $\begin{array}{l}\text { It has developed a new model of } \\
\text { automated grading system for oil palm } \\
\text { fruit is developed using the RGB } \\
\text { colour model and artificial fuzzy logic. }\end{array}$ & $\begin{array}{l}\text { The automated } \\
\text { system } \\
\text { implement in this case. } \\
\text { also }\end{array}$ \\
\hline
\end{tabular}




\begin{tabular}{|l|l|lr|}
\hline $\begin{array}{l}\text { D. S. Gaikwad et al. have proposed } \\
\text { image processing approach for grading } \\
\text { and identification of diseases on } \\
\text { pomegranate fruit.(2016) }\end{array}$ & $\begin{array}{l}\text { After feature extraction, images are } \\
\text { classified by using different } \\
\text { classification techniques. These are } \\
\text { artificial neural network, support vector } \\
\text { machine, fuzzy logic, and K-nearest } \\
\text { neighbour. }\end{array}$ & $\begin{array}{r}\text { This method } \\
\text { further use } \\
\text { classification } \\
\text { grading purpose. }\end{array}$ & $\begin{array}{r}\text { ind } \\
\text { and }\end{array}$ \\
\hline $\begin{array}{l}\text { S.Arivazhagan et al. have proposed fruit } \\
\text { recognition using colour and texture } \\
\text { features.(2010) }\end{array}$ & $\begin{array}{l}\text { The recognition is done by the } \\
\text { minimum distance classifier based } \\
\text { upon the statistical and co-occurrence } \\
\text { features derived from the Wavelet } \\
\text { transformed sub- bands. }\end{array}$ & \\
\hline
\end{tabular}

First, we extract the feature from the segmented portion of the images that are being used for the training and store in a feature database. After feature extraction, images are classified by using different classification techniques. These are artificial neural network, support vector machine, fuzzy logic, and K-nearest neighbour. S.Arivazhagan et al. ${ }^{[50]}$ have proposed fruit recognition using colour and texture features. The recognition has done by the minimum distance classifier based upon the statistical and co-occurrence features derived from the wavelet transformed. Experimental results on a database of about 2635 fruits from 15 different classes confirm the effectiveness of the proposed approach (Table 9).

\section{IV.DISCUSSION AND SUMMERIZATION}

This survey report outlines all the previous presented paper, with respect to used methodology, accuracy and year of publication is presented in (Graph 1). The subject of fruit detection and counting is undergoing from last few years. However the study used few numbers of methods applied as computer vision, pattern recognition, BPN, segmentation method, texture analysis; yield estimation, Hough transformation etc. Here we study the different methods applied in this field in last 10 year.

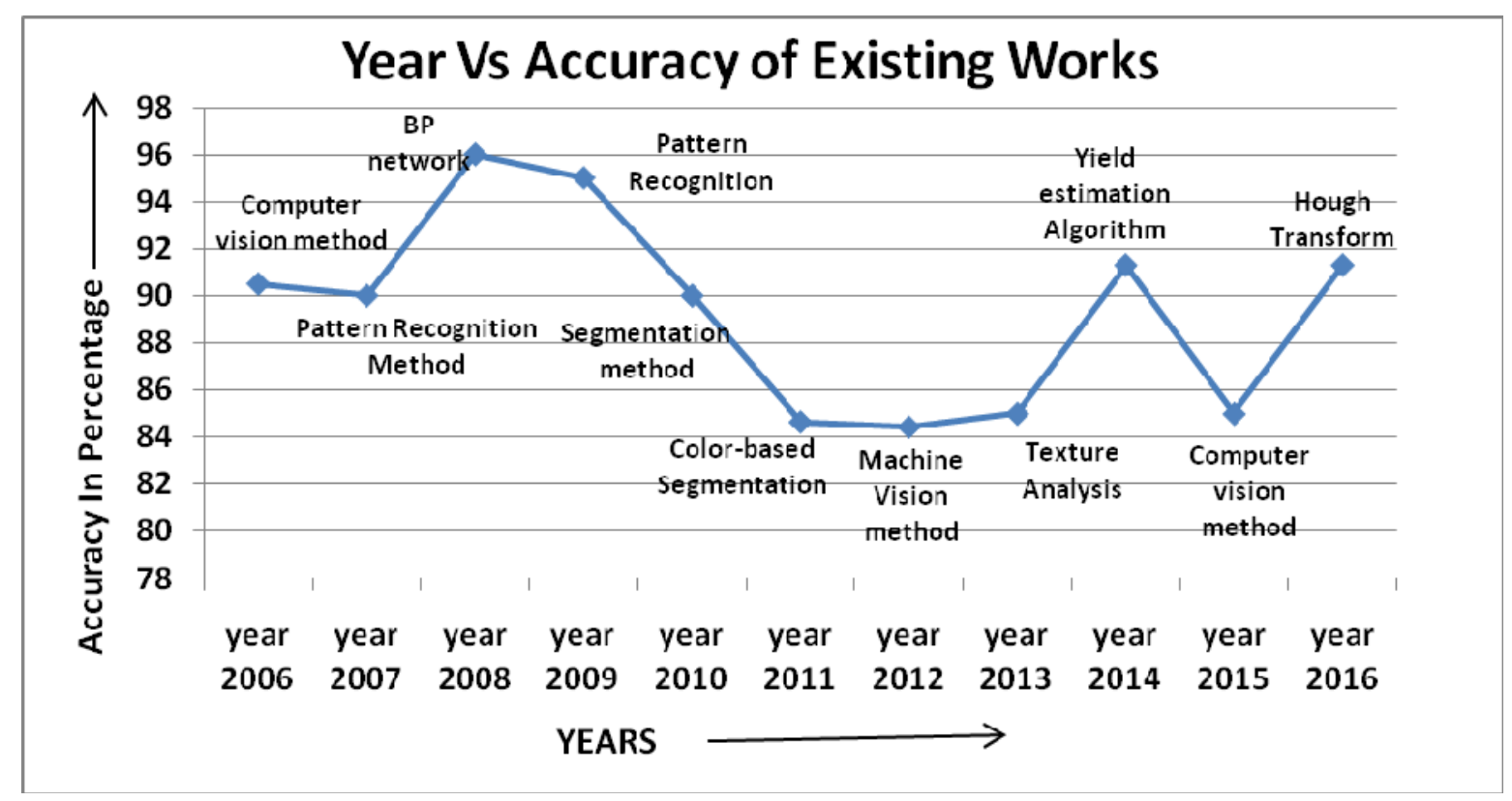

Graph 1 Year versus Accuracy of Existing Work

The summary of this study is as follows:-

- In the year 2006, Mohammad Bagher Lak, has proposed the computer vision method. In this method he has got $90.4 \%$ of accuracy for both detection and counting of fruits.

- In 2007, Zania S Pothen, has described new method i.e. pattern recognition. In his research work he has got $80 \%$ and $82 \%$ of accuracy for both detection and counting of apple fruits.

- In the year 2008, D. Jayas has proposed neural network. This method is a very effective method for classification and by his work he got the accuracy of $96 \%$ for quality analysis of fruits.

- In 2009 again pattern recognition method has used by M. Jonathan Wu and he has got better accuracy compare to previous one i.e. $94.5 \%$ for fruit detection.

- In 2010, K.paravati, has proposed the segmentation method and during his research work he has got $90 \%$ of accuracy for detection and grading of fruits. 
- In the year 2011, Peilin Li has proposed color-based segmentation method. In this case he has got fruitful result. He got the accuracy of $84.2 \%$ for citrus fruit detection.

- In 2012, H.N Patel has proposed the machine vision method. During his research work he has got $84.1 \%$ of accuracy for grading of fruits.

- D. Surya Prabha, in the year 2013 has proposed texture analysis method and he got the accuracy of $84.5 \%$ for fruits detection.

- Yield estimation algorithm has used by D.S. Gaikuwad and in his work he got the accuracy of $90.8 \%$ for fruits counting in the year 2014.

- In 2015 again machine vision method has used by Amruta Pandit in his review work and she has got the accuracy of $84.4 \%$ for recognition and quality analysis of fruits.

- In the year 2016, Uravashi Solanki has proposed Hough transform method. He has got the accuracy of $90.9 \%$ for fruit detection.

\section{CONCLUSION}

This paper presents the survey on, On-tree detection, counting and post harvest grading of fruits. This survey of recent works in this field should be very useful for researcher in this interesting area. In case of detection, various methods like k-means clustering, color-space segmentation, RGB color recognition, HSI technique etc are used. In the whole review case we have conclued that the k-means clustering segmentation is a very effective method for both mature and immature fruits detection. For counting of fruits there were very few work has been done. Mainly for counting of fruits morphological operation has been used. The paper reviews the recent developments in computer vision for the agricultural industry. Computer vision systems have been used increasingly in industry for inspection and quality evaluation purposes as they can provide rapid, economic, hygienic, consistent and objective assessment.

However, difficulties still exist, evident from the relatively slow commercial uptake of computer vision technology in all sectors. Even though adequately efficient and accurate algorithms have been produced, processing speeds still fail to meet modern manufacturing requirements. For grading, various classification methods are used. From the above studies all classification technique was evaluated accurately. But among all, artificial neural network and support vector machine techniques are give the better accuracy compare to other technique. Some of the future aspects are following which can help the researchers working in the same field of research

- The research area is not only limited for detection, identification and counting of on-tree fruits in agricultural field but also overlapping of fruits and shape recognition can be separated by using various algorithms.

- Grading of fruits is another wide area of research, that to know the quality of fruits and according to that price can be determine for commercial purpose.

- Mobile based application can be designed by using an automate on-tree fruits detection and counting technique that will help for providing quick and accurate solution.

The on-tree counting and post-harvest grading area of research can not be limite to above mentioned future scope. There are more other area where researcher have to explore for new innovation. In this review, as there are so many methods are proposed and implimented to detect, count and quality analysis of fruits using image processing and machnie vision technique. The main objective of the paper is to describe an overview of technical concepts used in the method existing in the litrature review.

\section{REFERENCES}

[1] Y. Song et al, C.A Glaxbey, G.W Hargon, G.Polder, J.A. Dieleman and G.W.A.M van der Heijden "Automatic fruit recognition and counting from multiple images", b i o s y s t ems eng i n e e r ing $118\left(\begin{array}{llll}2 & 0 & 1 & 4\end{array}\right) 203$ e2 15.

[2] Zeeshan Malik, Sheikh Ziauddin, Ahmad R. Shahid, and Asad Safi. "Detection and Counting of On-Tree Citrus Fruit for Crop Yield Estimation”, (IJACSA) International Journal of Advanced Computer Science and Applications, Vol. 7, No. 5, 2016.

[3] Mohammad Bagher Lak, Farik Husen and Amina Musafir. "Machine vision recognition algorithm development as the first stage of apple robotic harvesting machine vision", Computers and Electronics in Agriculture 36 (2006) 193_ 213.

[4] K. Parvati, B. S. Prakasa Rao and M. Mariya Das. "Image segmentation using gray-scale morphology and marker-controlled watershed transformation", AGRICULTURAL COMMUNICATIONS, 2010, 2(4): 9-15.

[5] Radnabazar Chinccullue, Suk LEE and Thomas F Burkes. . "Literature Review on Object Counting using Image Processing Techniques", International Journal of Advanced Research in Electrical, Electronics and Instrumentation Engineering (An ISO 3297: 2007 Certified Organization) Vol. 3, Issue 4, April 2014.

[6] Amruta Pandit and Jyoti Rangole. "Literature Review on Object Counting using Image Processing Techniques", computer vision and image understanding, 84. 1-29, (2001).

[7] D. S. Jayas, J. Paliwal and N. S. Visen. "Multi-layer neural networks for Image Analysis of Agricultural Products", New Zealand Journal of Agricultural Research, (March 2008) 52(3):1316-1327.

[8] Libin Zhang, Qinghue Yang, Yi Xun, Xieo Chen, Ting Yuan, Yuzhi Yun and Wei Li. "Recognition of greenhouse cucumber fruit using computer vision", International Journal of Security and Its Applications Vol. 7, No. 3, May, 2013.

[9] Zania S Pothen and Stiphen Nuske. "Texture-based Fruit Detection via Images using the Smooth Patterns recognition of the Fruit", J.agric. Engng Res., 2007, 77 (2), 119\}128 doi:10.1006/jaer.2000.0559, available online at http://www.idealibrary.com on $\mathrm{AE} *$ Automation and Emerging Technologies. 
[10] Palaniappan Annamalai and Won Suk Lee. "Citrus Yield Mapping System Using Machine Vision”, ISSN: 0028-8233 (Print) $1175-$ 8775 (Online) Journal homepage http://www.tandfonline.com/loi/tnza20.

[11] Annamalai. "Papaya size grading using central profile analysis of digital image", Paper Number: 031002 An ASAE Meeting Presentation.

[12] Q. M. Jonathan Wu, L. Yang, S.Lang and Q.M.J. Wu. "Fruit recognition method for automatic harvesting", International Journal of Security and Its Applications Vol. 7, No. 3, May, 2009.

[13] Sashi. D.Buluswar and Bruce A. Draper. "Color models for outdoor machine vision", AGRICULTURAL COMMUNICATIONS, 2014, 2(4): 9-15

[14] Ulzii-Orshikh Dorj, Malrey Lee and Sangsub Han. "A comparative study on tangerine detection, counting and yield estimation algorithm", Pattern Recognition 32 (1999) 1719\}1736.

[15] Minjun Wang, Jun Jhou, Weiyan Shang, Rufu Hu and Liang Gong. "a novel algorithm for green circuits detection based on reticulate gray ladder feature”, International Journal of Computer Applications (0975 - 8887) Volume 2 - No.1, May 2010.

[16] Alireza Khoshroo, Arman Arefi and Jalal Khodei. "Detection of Red Tomato on Plants using Image Processing Techniques", IOSR Journal of Electronics and Communication Engineering (IOSR-JECE) e-ISSN: 2278-2834,p- ISSN: 2278-8735.Volume 8, Issue 6 (Nov. - Dec. 2013), PP 01-05.

[17] A.R. JimeHnez, A.K. Jain, R. Ceres and J.L. Pons. "Automatic fruit recognition: a survey and new results using range/attenuation images", Vietnam J Compute Sci (2015) 2:25-33 DOI 10.1007/s40595-014-0028-3.

[18] Narendra V G and Hareesh K S. "quality inspection and grading of agricultural and food products by computer vision- a review", International Journal of Computer Applications (0975 - 8887) Volume 2 - No.1, May 2010.

[19] Tadhg Brosnan and Da-Wen Sun. "Inspection and grading of agricultural and food products by computer vision systems a review", Computers and Electronics in Agriculture 36 (2002) 193213.

[20] J.C. Noordam, G.W. Otten, A.J.M. Timmermans and B.H. van Zwol. "High speed potato grading and quality inspection based on a color vision system", J Food Sci Technol (March-April 2012) 49(2):123-141 DOI 10.1007/s13197-011-0321-4.

[21] Krishna Kumar Patel, A. Kar, S. N. Jha and M. A. Khan. "Machine vision system: a tool for quality inspection of food and agricultural products", IOSR Journal of Electronics and Communication Engineering (IOSR-JECE) e-ISSN:2014).

[22] C. S. Nandi, B. Tudu and C. Koley. "machine vision based techniques for automatic mango fruit sorting and grading based on maturity level and size", Hindawi Publishing Corporation Discrete Dynamics in Nature and Society Volume 2008, Article ID 384346, 8 pages doi: $10.1155 / 2008 / 384346$.

[23] Ms.Rupali, S.Jadhav and Prof S.S.Patil. "Fruit quality management system based on image processing", SSRG International Journal of Computer Science and Engineering (SSRG-IJCSE) - volume 2 issue 6 June 2015.

[24] K. Parvati, B. S. Prakasa Rao and M. Mariya. "Image Segmentation Using Gray-Scale Morphology and Marker-Controlled Watershed Transformation", Journal of Emerging Trends in Computing and Information Sciences (O2009-2010 CIS Journal. All rights reserved.

[25] Miss. Anuradha Gawande and Prof.S.S.Dhande. "Implementation of Fruits Grading and Sorting System by Using Image Processing and Data Classifier", J Food Sci Technol (March 2015) 52(3):1316-1327 DOI 10.1007/s13197-013-1188-3.

[26] S.Arivazhagan, R.Newlin, Shebiah and S.Selava. "fruit recognition using color and texture features", TCTS Labs, Facult'e Polytechnique de Mons Multitel Building, Avenue Copernic 1, Parc Initialis, B-7000, Mons, Belgium phone: + (3265) 374745, fax: + (3265) 374729.

[27] D. Surya Prabha and J. Satheesh Kumar. "Assessment of banana fruit maturity by image processing technique", Journal of Food Engineering 76 (2006) 506-523.

[28] Devrim Unay and Bernard Gosselin. "Thresholding-based segmentation and apple grading by machine vision", International Journal of Computer Applications (0979 - 8889) Volume 2 - No.1, May 2011.

[29] M.Z. Abdullah, J. Mohamad-Saleh, A.S. Fathinul-Syahir and B.M.N. Mohd-Azemi. "Discrimination and classification of fresh-cut star fruits (Averrhoa carambola L.) Using automated machine vision system”, J Food Sci Technol (March-April 2015) 50(2):123-142 DOI 10.1007/s13197-011-0321-6.

[30] Narendra V G and Hareesh K S. "proposed quality inspection and grading of agricultural and food products by computer vision- a review", Department of Food Engineering, Hebei Normal University of Science \& Technology,Changli 066600, Hebei Province, P.R. China.

[31] Krishna Kumar Patel, A. Kar, S. N. Jha and M. A. Khan. "Machine vision system: a tool for quality inspection of food and agricultural products", International Journal of Advancements in Technology.

[32] Van Huy Pham and Byung Ryong Lee. "an image segmentation approach for fruit defect detection using k-means clustering and graph-based algorithm", George, Int J Adv Technol 2015.

[33] Haisheng GAO, Jinxing Cai and Xiufeng Liu. "Automatic Grading of the Post-Harvest Fruit: A Review", International Journal of Advancements in Technology.

[34] Mathew George. "Multiple fruit and vegetable sorting system using machine vision", Sakya Sarkar, Somsubhra Gupta Department of Information Technology JIS College of Engineering, Kalyani.

[35] Sakya Sarkar and Somsubhra Gupta. "a comprehensive approach for fruit pattern recognition under the framework of digital image processing”, International Journal of Computer Applications (0975 - 8887) Volume 93 - No.11, May 2014.

[36] Jagadeesh D.Pujari, Rajesh Yakkundimath and Abdulmunaf S. Byadgi. "Recognition and classification of normal and affected agriculture produce using reduced color and texture features", international Journal of Computer Applications (0974 - 9856) Volume 94- No.12, May 2015.

[37] H.N Patel, R.K Jain and M.V Jyoshi. “Automatic Segmentation and Yield Measurement of Fruit using Shape Analysis”, International Journal of Computer Applications (0975 - 8887) Volume 45- No.7, May 2012.

[38] W.S. Qureshi. "Machine vision for counting fruit on mango tree canopies", Department of Mechatronics Engineering, National University of Science and Technology, H-12 Islamabad Pakistan Asian Institute of Technology, Klong Luang.

[39] Shuiguang Deng. "a feature-selection algorithm based on Support Vector Machine-Multiclass for hyper spectral visible spectral analysis", Contents lists available at SciVerse Science Direct, Journal of Food Engineering journal homepage.

[40] Woo Chaw Seng. "a new method for fruits recognition system", Computer Science \& Information Technology University of Malaya.

[41] Miss. Anuradha Gawande. "Implementation of Fruits Grading and Sorting System by Using Image Processing and Data Classifier", SSRG International Journal of Computer Science and Engineering (SSRG-IJCSE) - volume 2 issue 6 June 2015.

[42] Peilin Li. "Study on citrus fruit image data separability by segmentation Methods", available online at www.sciencedirect.com procedia engineering 00 (2011) 000-000 www.elsevier.com/locate/procedia available.

[43] Jagadeesh Devdas Pujari. "Grading and classification of anthracnose fungal disease of fruits based on statistical texture features", International Journal of Advanced Science and Technology Vol. 52, March, 2013.

[44] Gurea Tonguc. "fruit grading using image processing technique", Journal of agricultural malaria, 2009. 
[45] Uravashi Solanki. "a survey on detection of disease and fruit grading. Classifier is used for classifying images based on their features "Available on international journal of innovative research. Volume 58.2015.

[46] Jagadeesh D.Pujari. "Recognition and classification of normal and affected agriculture produce using reduced color and texture features", International Journal of Computer Applications (0975 - 8887) Volume 93 - No.11, May 2014.

[47] Queerzzs akeemu amin. "Image processing for quality and safety control in Hortiagricultural industries", THEASIAN JOURNAL OF HORTICULTURE Volume 8 | Issue 1 | June, 2013 | 364-373.

[48] Jagadeesh Devdas Pujari. "Grading and classification of anthracnose fungal disease of fruits based on statistical texture features".

[49] D. S. Gaikwad. "Image Processing Approach for Grading and Identification of Diseases on Pomegranate Fruit: an overview", (IJCSIT) International Journal of Computer Science and Information Technologies, Vol. 7 (2) , 2016, 519-522.

[50] S.Arivazhagan. "Fruit Recognition using Color and Texture Features. The recognition is done by the minimum distance classifier",

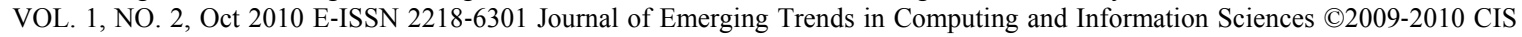
Journal. All rights reserved.

\section{AUTHOR PROFILE}

Prabira Kumar Sethy has received his Master of Technology degree in
Communication Engineering from IIT(ISM) Dhanbad. He has been a Lecturer
in Sambalpur University, Odisha, India. His research interest is Image
Processing. He has published more than 20 no. of Publication in International
Journal and Conferences.

